Roberto V. Giménez Morell.

Departamento de Dibujo. Universidad Politécnica de Valencia.

\author{
M므 Dolores Vidal Alamar. \\ Departamento de Dibujo. Universidad Politécnica de Valencia.
}

\title{
La fotografía como medio creativo y auxiliar de la perspectiva.
}

\author{
TIPO DE TRABAJO \\ Comunicación virtual.
}

PALABRAS CLAVE

Dibujo, perspectiva, fotografía.

KEY WORDS

Drawing, perspective, photography.

RESUMEN

La destreza espacial se puede adquirir y desarrollar a través del aprendizaje y de la práctica por tanto constituye una de las más importantes capacidades a tener en cuenta por el artista para afrontar con éxito la realización de dibujos creativos mediante la perspectiva como método de representación. Aprender a ver, visualizar, analizar imágenes, recrear imágenes mentales, son algunas de las actividades directamente relacionadas con la experiencia visual que cada individuo posee. Planteamos un cambio en el concepto de la perspectiva en el ámbito artístico con el fin de optimizar y facilitar su utilización y manejar con soltura los medios que es capaz de proporcionar. Para ello se antepone el carácter perceptivovisual sobre el carácter matemático, quedando éste último reducido a la mera base geométrica y teórica. La utilización de la fotografía es básica aquí para conseguir un entendimiento mayor y más rápido de los elementos perspectivo-visuales y del comportamiento formal de su estructura espacial. Veremos los resultados tanto en los bocetos con una base intuitiva y sensorial, hasta el rendering que utiliza las técnicas gráfico-pictóricas más diversas, así como en los dibujos narrativos, que nos llevarán a valorar el uso de la fotografía como material creativo en el proceso de la representación.

\section{ABSTRACT}

Spatial skills can be acquired and developed by learning and practicing. Therefore it constitutes one of the most important capacities used by artists in order to draw using perspective successfully as a creative method of representation. Learning to see, to visualize, to analyze images, to recreate mental images - these are some of the activities directly related to the visual experience that every person possesses. Our aim is to change the concept of perspective in the artistic field in order to optimize and to facilitate its utilization and to handle with fluency the means that it is capable of providing. While its perceptive and visual character is enhanced, its mathematical-geometric character is diminished to a mere theoretical base. The utilization of photography is basic here to obtain a major and a faster understanding of the visual elements and of the spatial structure. We will see the results in the freehand sketches made with an intuitive and sensory base, up to the rendering that uses the most diverse graphical-pictorial techniques, as well as in narrative drawings, which will lead us to value the use of photography as a creative material in the process of representation. 


\section{CONTENIDO}

\section{Introducción: La imagen fotográfica y el aprendizaje visual}

“En el aprendizaje de la expresión gráfica es de gran importancia aprender a mirar las formas tridimensionales antes de reproducirlas dibujando del natural. En el dibujo en perspectiva es indispensable una precisión del resultado lo más fiel posible, labor a la que contribuye muy positivamente la experiencia en dibujo del natural y en la fotografía"i

Cada vez se recurre con más frecuencia a imágenes pictóricas y fotográficas como modelo de análisis como se puede apreciar en los tratados de dibujo modernos, especialmente entre los autores anglosajones, y como vamos a ver ocupan un lugar muy importante en el uso y asimilación de la visión perspectiva. La comprensión del espacio y de las formas tridimensionales representadas es mayor cuanto menor sea el esfuerzo que debe realizarse en su lectura. Al ser la fotografía, una representación bidimensional, muestra su efectividad como lenguaje al resultar inmediata la asociación que mentalmente establecemos entre el objeto fotografiado y el objeto real. Es tal el mimetismo alcanzado, que en algunos periodos recientes del arte pictórico se ha hablado de "mimetismo fotográfico" para designar estilos de corte hiperrealista o de realismo figurativo. Es por ello que la fotografía puede ser y es un vehículo esencial para emplear con éxito la perspectiva.

Podemos establecer las siguientes características positivas de la fotografía como elemento auxiliar del artista y como no, también como modelo didáctico para la enseñanza de la perspectiva:

- La fotografía exige un mínimo esfuerzo de lectura espacial y por tanto reduce la exigencia habitual de poseer una "habilidad espacial" innata.

- Nos “congela" la imagen real, permitiendo analizar la estructura espacial de los objetos.

- Nos ofrece una información fácilmente asequible sobre la construcción perspectiva (puntos de fuga y elementos visuales) evitando la abstracción y la ambigüedad que a menudo supone el lenguaje geométrico con su esquematismo de líneas y su dificultad de lectura.

- Cuenta con el gran bagaje de la experiencia visual sobre la lectura y comprensión de imágenes que el individuo ha ido adquiriendo en una sociedad dominada por la cultura visual.

La relación de la fotografía y de la visión en su proceso perceptivo es asimismo significativa y nos da una idea del potencial de la imagen fotográfica en este campo tan cercano al del dibujo de representación perspectivo. De hecho la psicología de la percepción se ha ocupado de indagar la constancia de las características de los objetos percibidos en relación con el espacio geométrico que, por otra parte, rige las leyes de la perspectiva. Una de las mayores autoridades en la materia, el Dr. James J. Gibson ${ }^{2}$ hacía uso tanto de dibujos perspectivos como de comportamientos visuales en determinadas situaciones espaciales, estableciendo ejemplos fotográficos que se sintetizan gráficamente: las diferentes texturas que una fotografía puede mostrar, las relaciones del tamaño de los objetos con la distancia y con el ángulo visual, los gradientes de profundidad, la constancia del brillo y la sombra, el traslapo, o la percepción de la distancia en su conocido tratado sobre la percepción del mundo visual son algunos de los casos ilustrados por Gibson.

La fotografía ha sido igualmente empleada en la elaboración de modelos con maquetas para dar un aspecto real a los proyectos y también se ha desarrollado la técnica del fotomontaje para mostrar el proyecto de nuevo edificio y ubicarlo en el entorno urbano existente. "La photographie est un procedé tout à fait remarquable de mise en perspective puisquélle permet d'établir instantanément sur la pellicule une image en projection conque" ("La fotografía es un procedimiento completamente notable de la puesta en perspectiva porque permite establecer instantáneamente sobre la película una imagen en proyección cónica") ${ }^{3}$. Estas técnicas han sido adaptadas a la nueva tecnología digital con la aparición de los programas de ordenador de modelado en 3D. Con las cámaras digitales el proceso del fotomontaje se hace más manejable permitiendo que el medio fotográfico siga hoy siendo operativo en este campo de aplicación.

Una de las aplicaciones más directas de esquemas fotográficos para obtener información perspectiva es la restitución de los elementos visuales y perspectivos por la inmediatez y el paralelismo de resultados con la perspectiva dibujada. La equivalencia de conceptos es total y absoluta lo que nos permite extrapolar los trazados obtenidos. Por otra parte la fidelidad visual de la imagen fotográfica viene a complementar el grado de abstracción que el dibujo proyectivo conlleva en ocasiones, aún a pesar de que la perspectiva cónica es el sistema de representación más "visual" de todos los que comprende la geometría descriptiva.

Nos vamos a centrar pues en este último sistema, la perspectiva cónica, defendiendo -como lo venimos haciendo desde hace años- la postura intuitivo-visual más propia de los modelos anglosajones, frente a la tradicional matemático-proyectiva procedente de la escuela mongiana de gran influencia histórica en España ${ }^{4}$.

La utilización de la fotografía como elemento auxiliar entre los pintores fue ocupando poco a poco un lugar importante desde finales del siglo XIX, donde pintores como el francés Edgar Degas (1834-1917) o el checoeslovaco Alphonse Mucha (1860-1939) recurrieron a ella, especialmente para sus modelos y estudios de figura. Anteriormente el pintor italiano Canaletto (1697-1768) había empleado la 
cámara oscura para el encuadre de sus paisajes venecianos. Ya en el siglo XX la fotografía se hace habitual entre los artistas, tanto en los fotomontajes como en ciertos realismos, entre los que el hiperrealismo destaca por adoptarla como modelo de estética plástica.

A nosotros nos interesa en particular el valor informativo que la fotografía presta al dibujo de perspectiva. Quizás es en el paisaje urbano con sus edificios y calles, alineamiento de objetos o repeticiones modulares en donde el paralelismo entre ambas disciplinas sea más evidente y en donde se puede sacar mayor provecho de esta relación. Si nos preguntamos ¿qué información podemos tener al observar una fotografía como la de la figura 1?

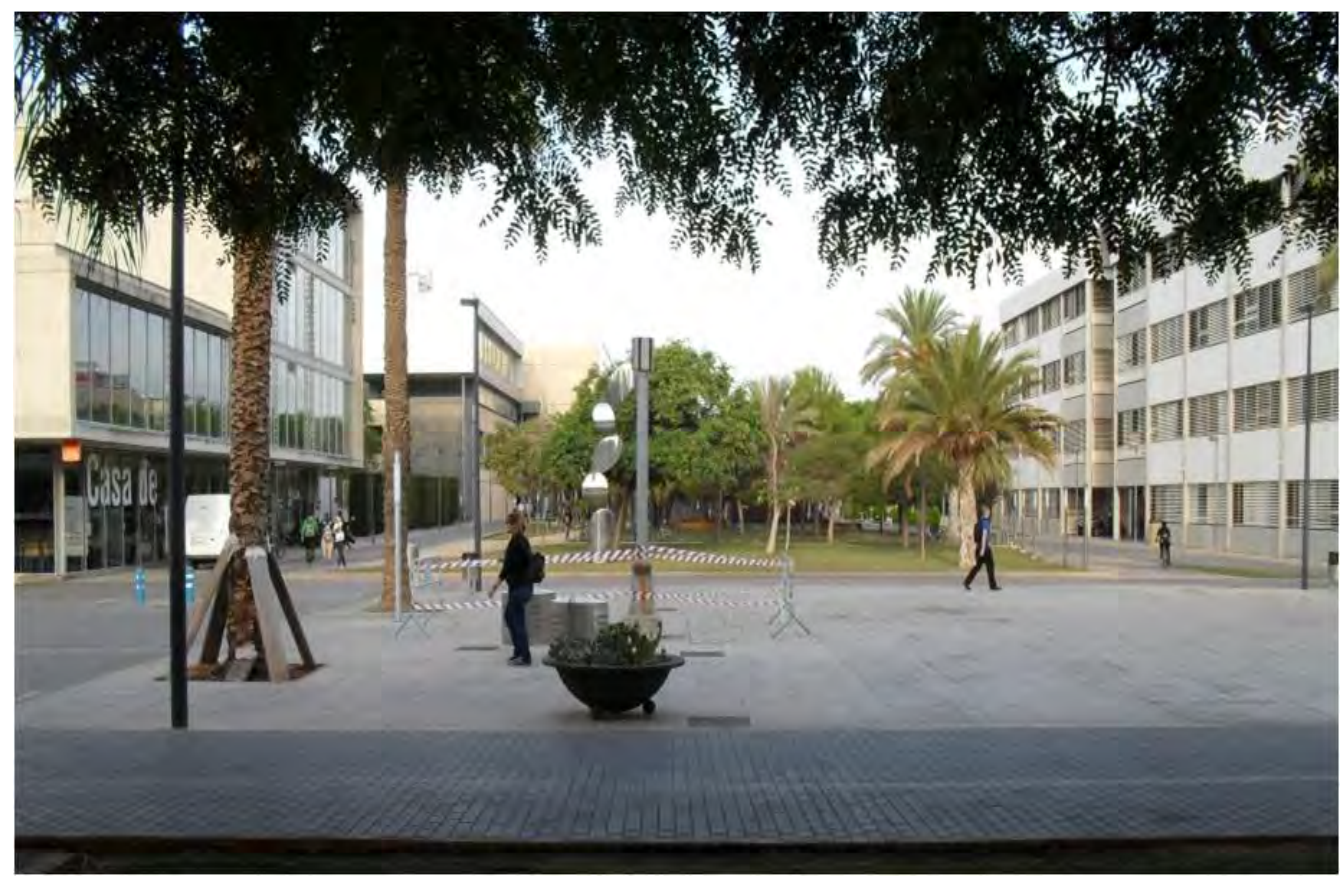

Fig. 1. Fotografía del campus de la Universidad Politécnica de Valencia

Simplemente llevando las líneas horizontales de las caras escorzadas de los edificios a converger, obtenemos el punto de fuga P y la línea del horizonte L.H. (fig.2). Es una información básica pero casi directa: solo hay que hacer una pequeña restitución de líneas.

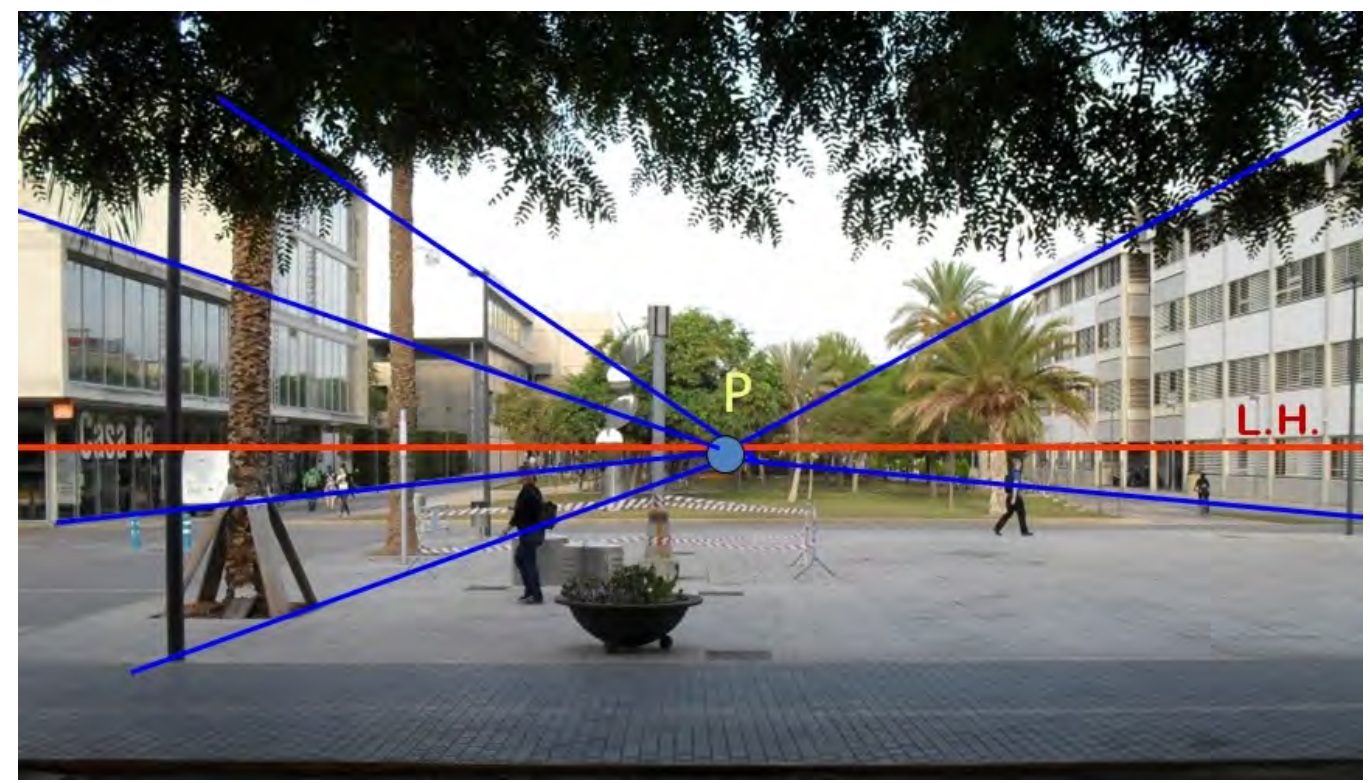

Fig. 2 Restitución básica de la perspectiva. 


\section{La fotografía como fuente de información para el artista}

Además de estos elementos perspectivos elementales la pregunta sería ¿Qué más podemos obtener de una fotografía que nos pueda ser útil para aplicarlo a un dibujo o una pintura? La respuesta a esta pregunta nos conduce a enumerar los puntos siguientes:

- Podemos obtener la composición.

- Los elementos básicos del sistema perspectivo: el punto de vista y su posición. El plano del cuadro y su disposición.

- El tipo de perspectiva frontal o de un punto de fuga. Punto de distancia.

- Perspectiva oblicua o de dos puntos de fuga. Restituciones.

- Perspectiva de cuadro inclinado o de tres puntos de fuga. Restituciones.

- Proporción y escalas.

- La figura humana y el entorno arquitectónico.

Sobre un concepto dado se capta con la cámara aquella situación que mejor evidencia el contenido que se pretende representar y su organización en el formato, es decir la composición. Diferentes parámetros propios de la perspectiva se pueden introducir aquí, como el tipo estructural de objetos, la posición del punto de vista, el tipo de perspectiva de uno dos o tres puntos de fuga, la escala, etc.

En la siguiente imagen se han obtenido diversos elementos perspectivo-visuales como el punto de vista V, la altura de visión L.H. y el punto de distancia $D$ que regula el gradiente de profundidad, datos que pueden sernos de gran utilidad al tenerlos materializados sobre "una porción de realidad" tangible visualmente hablando, una realidad que podemos analizar en un nivel de representación bidimensional. (fig.3).

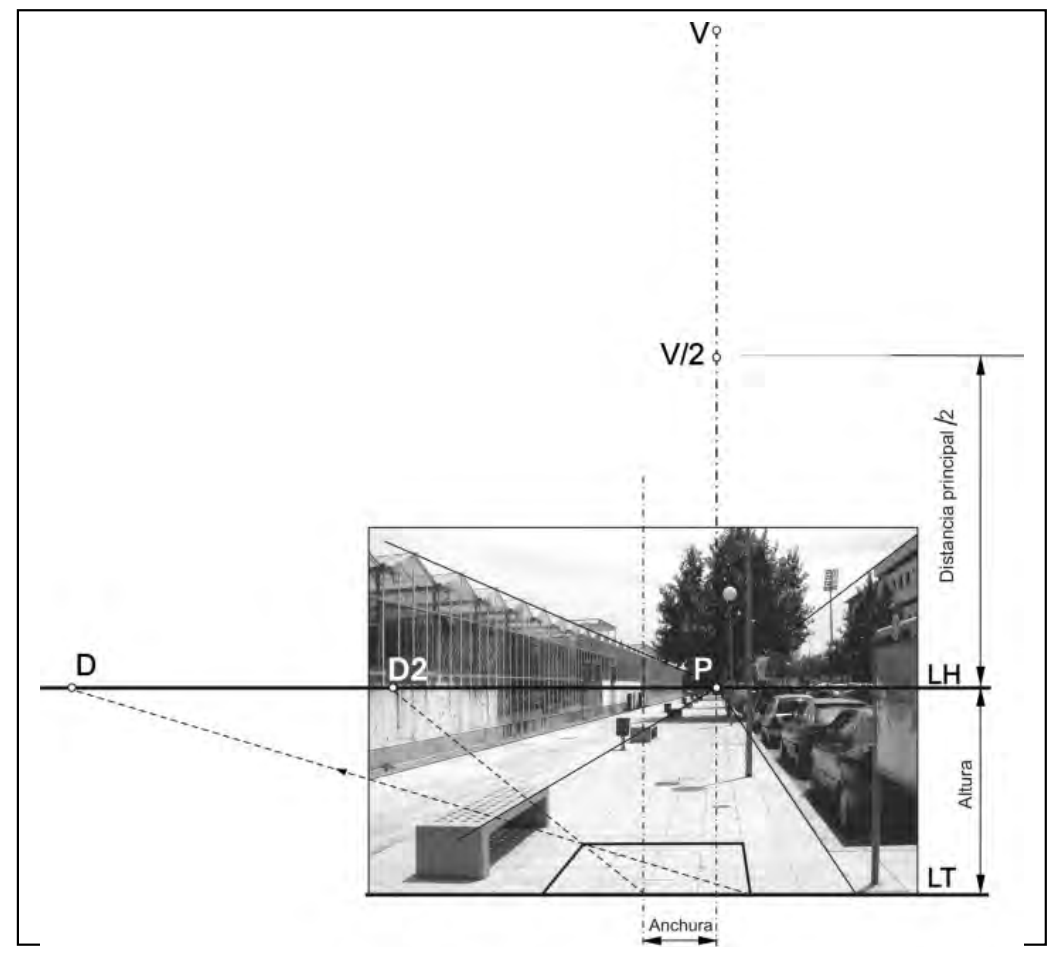

Fig. 3. Fotografía del campus de la Universidad Politécnica de Valencia.

La restitución de elementos también puede realizarse a partir de un simple bodegón, así podemos entender mejor las direcciones de las fugas de las distintas partes, si es que abundan las formas y volúmenes geométricos en los objetos, tales como rectángulos, cilindros, cubos, etc. Tal es el caso del siguiente ejemplo que mostramos a continuación (fig.4). 


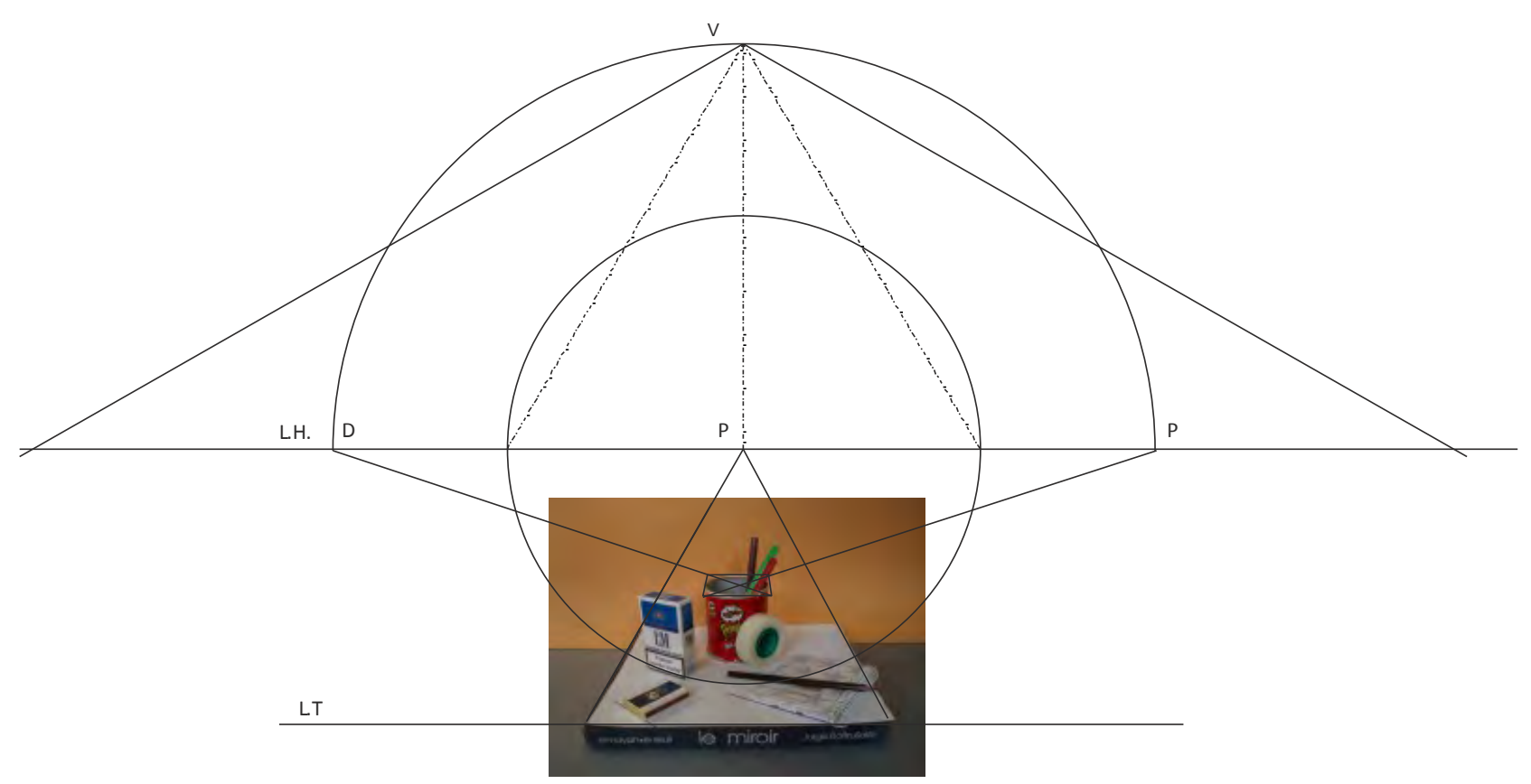

Fig. 4 Fotografía con la restitución de los puntos de fuga de los objetos mostrados y el cono visual

La siguiente ilustración nos muestra como el dibujante puede utilizar la estructura obtenida para construir las diversas formas. (fig.5).

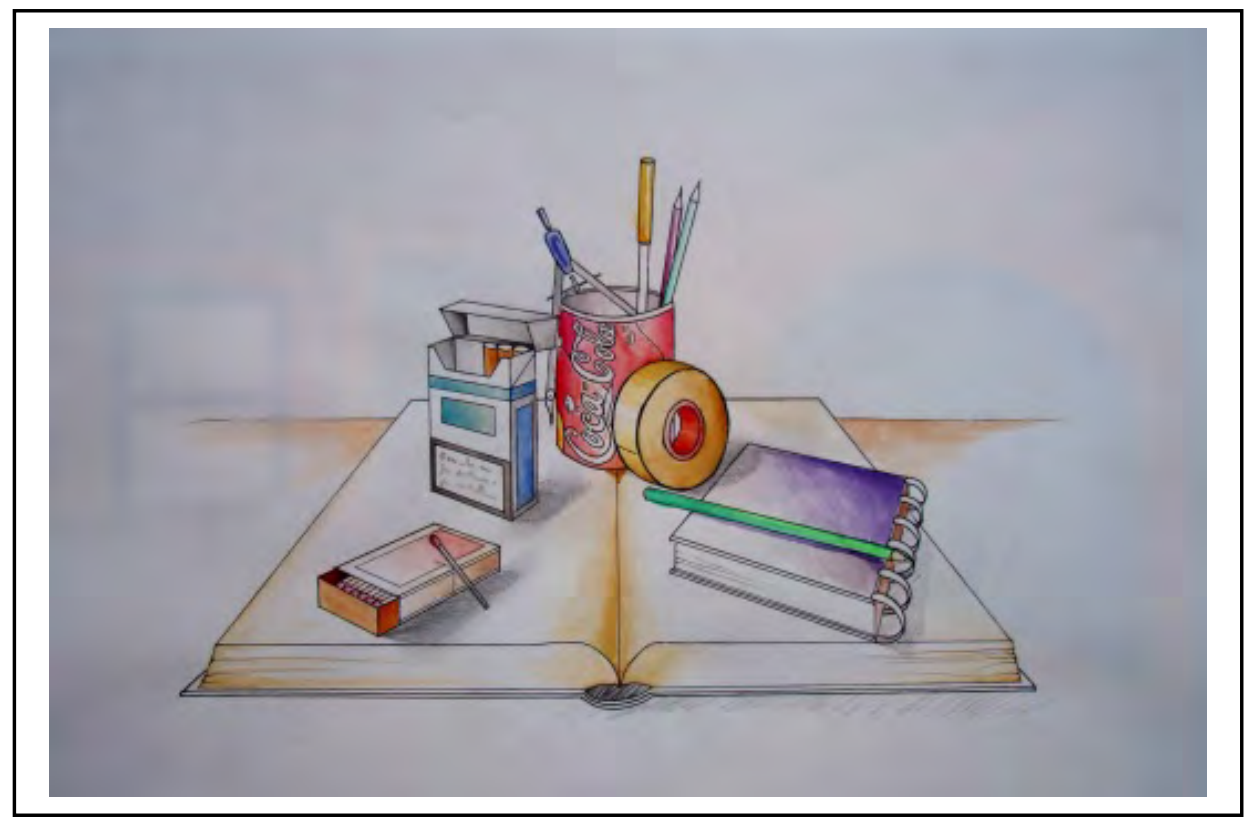

Fig. 5. Rodrigo Rodríguez. Objetos.

Claro que puede ser un tanto aparatoso realizar una restitución de estas características por el espacio extra que se requiere. Hay veces que todo este aparataje no es necesario y la simple observación visual es suficiente para construir un dibujo sólido a mano alzada (figuras 6 y 7). Solamente hay que reconocer el tipo de perspectiva que la vista genera y cuidar la proporción, especialmente en las formas sometidas a gradiente o escorzo, teniendo en cuenta el factor personal de la interpretación artística que es lo que hace expresivo un dibujo y por el que no es necesario que tenga una exactitud matemática. 


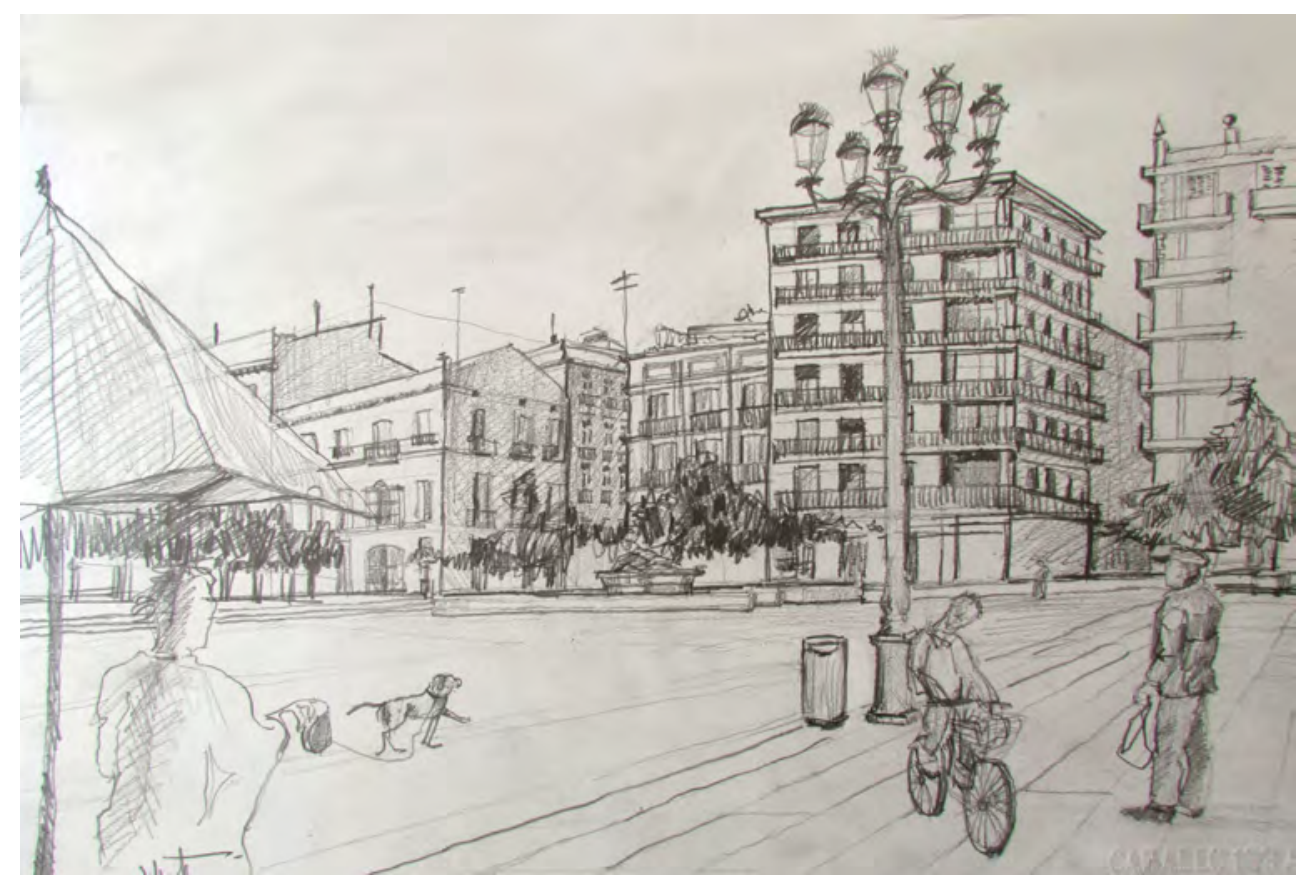

Fig. 6 Vicente Prieto. La plaza de la Virgen de Valencia.

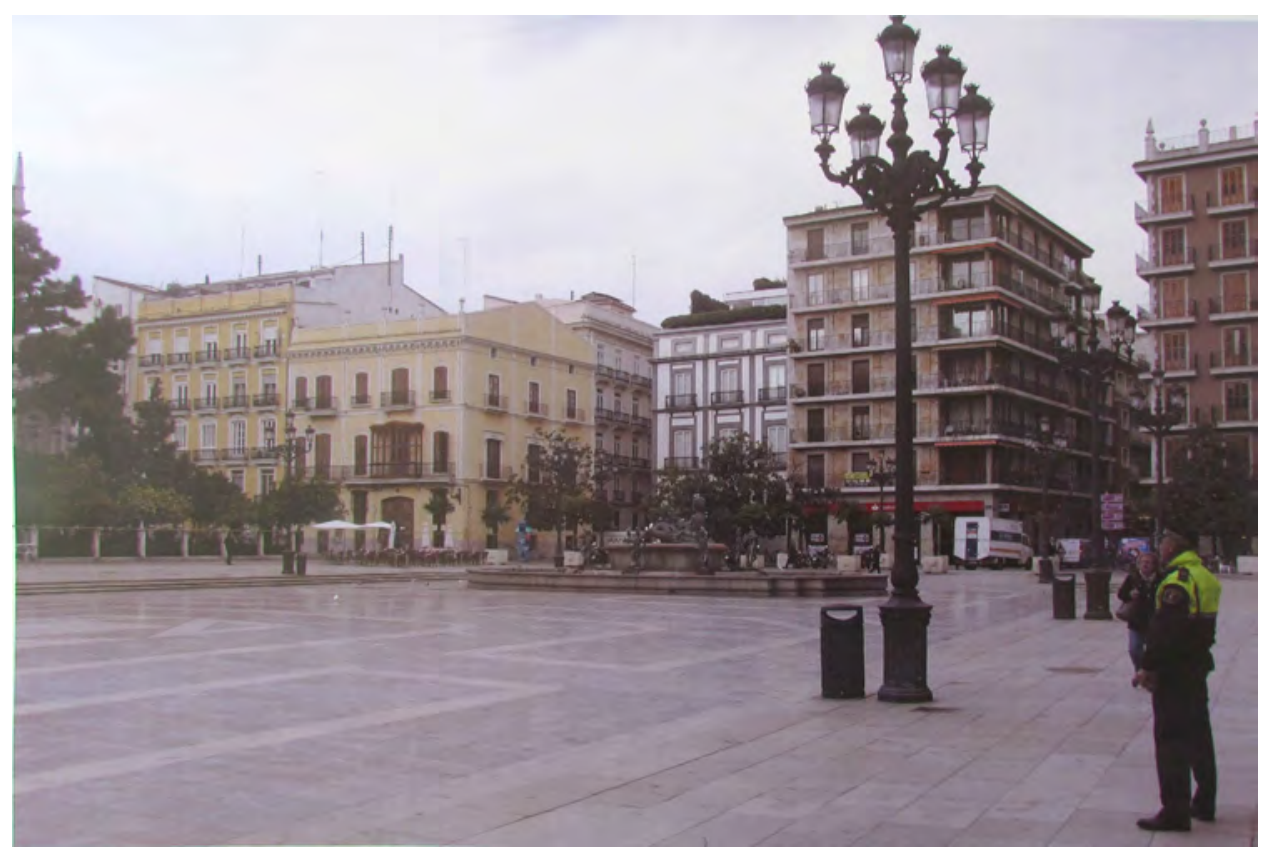

Fig 7. Fotografía de la Plaza de la Virgen de Valencia.

Precisamente este último factor es el que queremos mostrar en los siguientes dibujos. Ya sea por el trazo ya por el carácter de la mancha, la plasticidad de cada dibujo surgirá de manera natural en el artista (fig.8). En este caso la información que nos da la fotografía es una perspectiva angular de dos puntos de fuga y unas relaciones de proporción de la figura con respecto al marco del edificio (fig.9). 


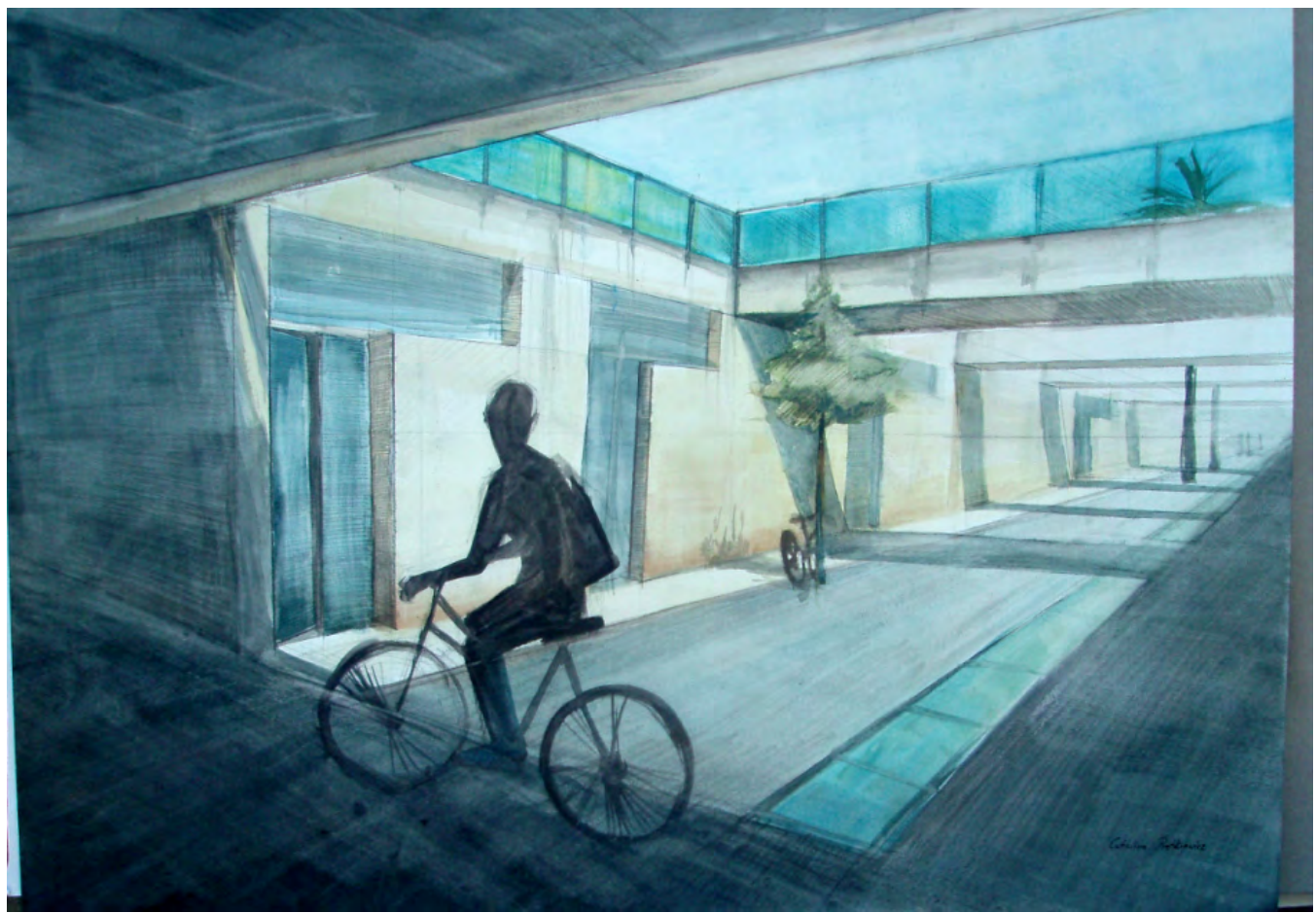

Fig. 8. Catalina Pretkievicz. Campus de la UPV.

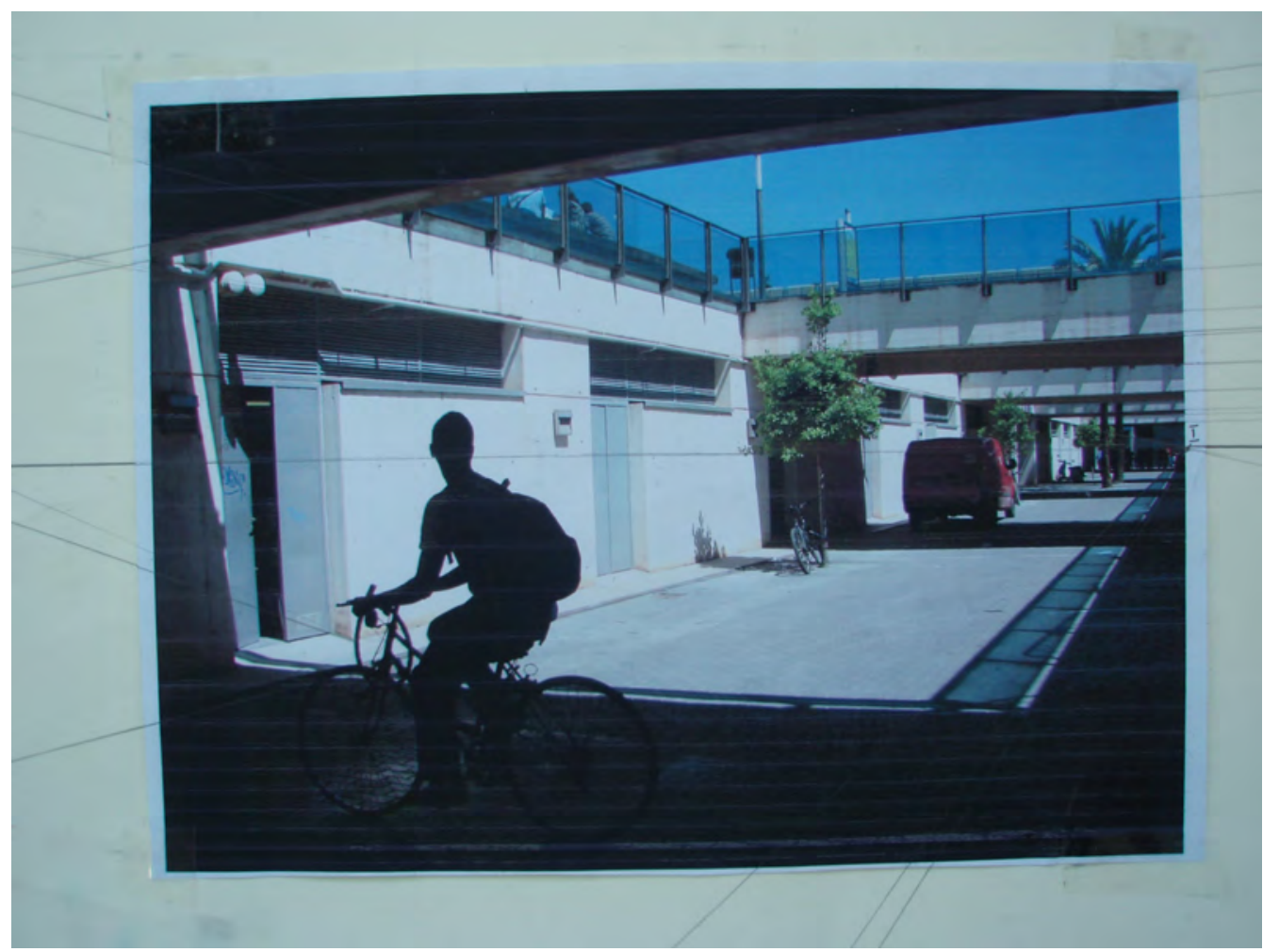

Fig. 9. Fotografía del campus de la U.P.V.

El poder de transformación de la realidad tomando como referente la fotografía se nos revela en la siguiente obra que aprovecha su información perspectiva (fig.10 y fig.11), donde la imaginación y la creación demuestran ese factor plástico característico del artista. 


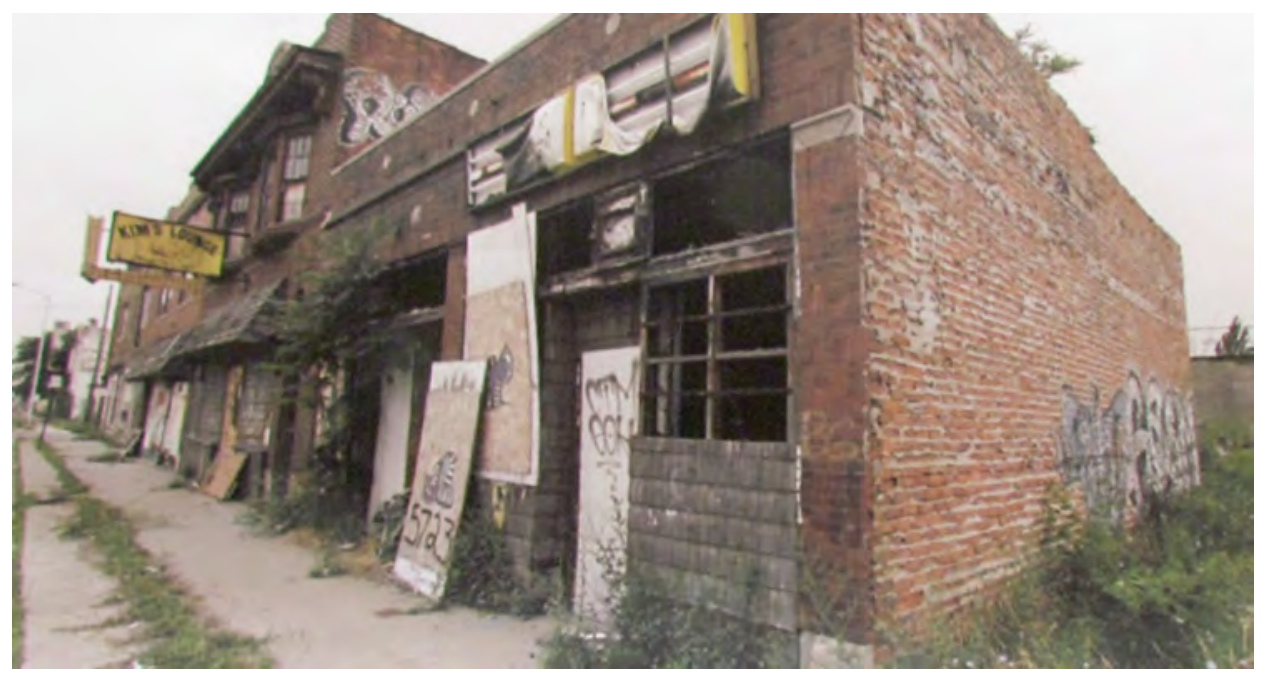

Fig. 10. Fotografía Ruínas.

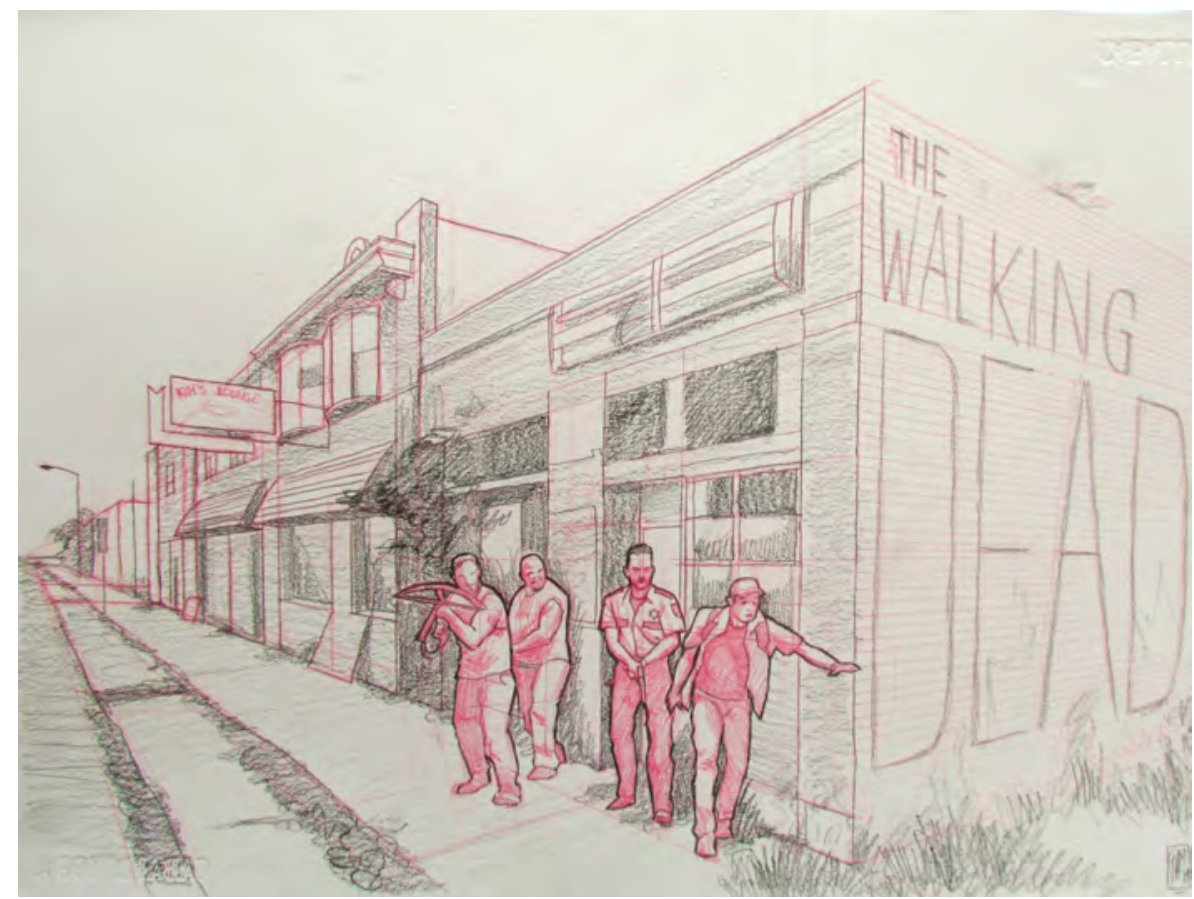

Fig. 10. Gómez Mascarell. Ruínas.

\section{Conclusiones}

De antemano es preciso admitir que jugamos con ventaja ante dos hechos importantes, que son por un,a parte la credibilidad iconográfica atribuida a la fotografía como imagen "real" al menos visualmente hablando y por otra la estructura geométricoproyectiva que la perspectiva y la fotografía tienen en común.

De ambas, se extrae otra ventaja: partimos de una imagen bidimensional sobre la cual el observador reconstruye la realidad y claro que el dibujo en perspectiva es también una imagen bidimensional. A partir de aquí podemos extraer algunas conclusiones como éstas:

La fotografía ofrece modelos complejos que transmiten gran cantidad de información sobre los mismos pero que exigen poco esfuerzo para asociarlos con los reales dada la cultura visual de nuestro ámbito cultural. En este sentido las fotografías ofrecen una información 
geométrico-perspectiva, como hemos visto y además información acerca de la luz (claroscuro) que modela los objetos y la definición de texturas. No obstante esta información es complementaria con la que podemos tener al realizar un boceto o un dibujo más acabado frente al referente real.

En la fotografía el artista se identifica fácilmente con el punto de vista de la cámara, convirtiéndose en el punto de vista psicológico de la escena y por ende, en el punto de vista o punto de proyección de la perspectiva. La identidad del Plano del Cuadro perspectivo con el papel fotográfico establece asimismo una identificación entre los límites de ambos, desplazando el concepto abstracto de "planos infinitos" y de puntos del infinito como son los puntos de fuga.

Se trata de una intervención intencionada del encuadre, por producirse de manera espontánea. El campo de visión queda acotado tal como ocurre en la perspectiva, evitándose el impulsivo e inconsciente movimiento de ojos o de la cabeza para obtener una información visual completa de nuestro entorno, que con frecuencia nos lleva a situaciones complejas en el montaje espacial de la escena ${ }^{5}$. A este respecto se pueden establecer comparaciones entre el cono visual en perspectiva y los diferentes objetivos de una cámara fotográfica. El objetivo de la cámara ilustra empíricamente el principio perspectivo de "ver" desde un único punto de vista (y no con dos, como ocurre en la visión directa que es binocular).

Sin embargo, es justo decir que no es totalmente coincidente la analogía entre la percepción visual directa y la percepción de la "realidad fotográfica". Congelar la realidad no es lo mismo que percibirla con todos los sentidos, pero podemos decir que para los objetivos concretos que nos hemos marcado cumple con creces el papel que le hemos asignado aquí.

Ya sea que se calque, que se copie la imagen, o que sirva ésta de referente para hacer la propia construcción, el fin es utilizar la información que la fotografía nos da. La perspectiva no es un fin en sí mismo, sino un dato importante acerca de la estructura de los objetos y del espacio. En este sentido es importante no dejarse llevar por la rigidez de su propia estructura. A partir de ahí es el factor personal, la creatividad y el componente artístico el que dará valor al dibujo, a la ilustración o a la pintura.

\section{FUENTES REFERENCIALES Y NOTAS}

\footnotetext{
Vilanueva, Lluis. Perspectiva lineal. Su relación con la fotografía. Barcelona. Editorial

Politex. UPC, 1996. p. 109.

${ }^{2}$ Gibson, James J. La percepción del mundo visual. Buenos Aires. Ediciones Infinito. 1974 ( 1a edición en inglés 1953).

3 Janzten, Eric. Traité practique de perspective. Paris. Editions de la Villette, 1983.p.109.
}

${ }^{4}$ En la tesis doctoral titulada Lectura y evaluación del espacio tridimensional en la representación gráfico-geométrica.:Implicaciones didácticas del método directo de George L. Hood (Universidad Politécnica de Valencia, 2008), Viíctor M. Grassa expone las ventajas en el aprendizaje del modelo visual sobre el modelo matemático reivindicadas en la segunda década del siglo XX por el norteamericano George J. Hood (1877-1965) en el contexto de la enseñanza del sistema diédrico, que es quizás junto con el acotado, el sistema de representación más complicado de entender visualmente. Véase: http://apps.morelab.deusto.es/teseo/resource/thesis/lectura-yevaluacion-del-espacio-tridimensional-en-la-representacion-grafico-geometrica-implicaciones-didacticas-del-metodo-directo-degeorge-j-hood-en-la-codificacion-del-diedrico-directo.

\footnotetext{
${ }^{5}$ La libertad de movimientos de los ojos y de la cabeza hace que el tipo de escena que vemos pueda alterarse enormemente en cuanto a la estructura perspectiva se refiere, Con tan solo girar la cabeza un pequeño ángulo podemos pasar de una vista frontal a otra en ángulo, añadiéndose nuevos puntos de fuga. Véase en la colección Riunet de la Biblioteca de la Universidad Politécnica de Valencia diversos videos- objeto de aprendizaje de los autores de la comunicación con el tema "Errores de perspectiva", así como un módulo de aprendizaje dedicado a este tema.
}

http://hdl.handle.net/10251/16424; http://hdl.handle.net/10251/16276 